\title{
Returning unwanted medicines to pharmacies: prescribing to reduce waste
}

\author{
Emilie Bettington \\ Research fellow', \\ Jean Spinks \\ Research fellow ${ }^{1,2}$ \\ Fiona Kelly \\ Senior lecturer 2,3

\section{Amanda J Wheeler} \\ Professor of Mental Health ${ }^{2}$ \\ ${ }^{1}$ Centre for Applied Health \\ Economics \\ School of Medicine \\ Griffith University \\ Brisbane \\ 2 Menzies Health Institute \\ Queensland \\ Griffith University \\ Brisbane \\ ${ }^{3}$ School of Pharmacy \\ Griffith University \\ Gold Coast \\ Queensland
}

\section{Keywords}

expired medicines, left-over medicines, Pharmaceutical Benefits Scheme, Return Unwanted Medicines

Aust Prescr 2018;41:78-81 https://doi.org/10.18773/ austprescr.2018.015

\section{SUMMARY}

The Return Unwanted Medicines Project is a free and safe way for consumers to dispose of unwanted medicines at pharmacies.

In 2016 the Project collected over 704 tonnes of unwanted medicines. An audit found that the most commonly returned medicines were unexpired opened packets of medicines for the treatment of acute conditions. They included paracetamol, salbutamol and glyceryl trinitrate.

Doctors, pharmacists, nurses and consumers should be more aware of which repeat prescriptions of 'if required' medicines are needed.

In making decisions about the quantity of medicine to supply, prescribers need to consider patient access, adherence and cost.

It is the responsibility of all health professionals to encourage consumers to return unwanted medicines to their community pharmacy.

\section{Introduction}

The accumulation of unwanted medicines at home can result in accidental ingestion, or lead to confusion, and out-of-date medicines can become toxic or ineffective.' Disposal of these medicines in general household waste means they can end up in landfill or contaminate waterways and affect animal and plant life and potentially human life..$^{2-5}$

The collection and disposal of unwanted medicines is an important public health issue and is part of the Australian National Medicines Policy. ${ }^{6}$ The Return Unwanted Medicines (RUM) Project is a subsidised national scheme that allows unwanted medicines to be collected by any community pharmacy and disposed of by high-temperature incineration.?

In 2016, the RUM Project was audited by Griffith University. The aim was to identify the types and quantities of medicines being discarded, including prescription, pharmacist and pharmacy-only medicines (Schedules 4, 3 and 2 respectively), controlled medicines (Schedule 8), complementary medicines, unscheduled medicines and dose administration aids. This allows health professionals to better understand consumer behaviour and provides a starting point for discussions around quality use of medicines ${ }^{8}$ and prescribing practices.

\section{Why are some medicines prescribed but not used?}

There are various reasons why someone may obtain a medicine but not use all of it. Medicines often require titration or adjustment, antibiotic courses may not be finished, a medicine may not work, or it may cause an adverse effect and need to be stopped. Sometimes the pack size prescribed might be more than is required, especially for acute conditions such as pain or nausea and vomiting. In addition, people may keep spare medicines, such as a salbutamol inhaler at their work, which expire before they are fully used.

\section{Audit of unwanted medicines}

The 2016 audit assessed the types and amounts of medicines returned via the RUM Project at the three national incineration sites (Brisbane, Perth and Melbourne). On average, 13000 RUM bins per month are collected for incineration. ${ }^{7}$ The audit aimed to examine the contents of a nationally representative sample of 423 RUM bins. ${ }^{9}$ This represented approximately $0.26 \%$ of the total number of bins collected between July 2015 and June 2016. ${ }^{7}$ In total, 452 bins were assessed in terms of percentage filled, proportion of loose tablets and whether they contained inappropriate items. Twenty-nine bins were excluded from the audit as 
they were less than $50 \%$ full (4 bins), contained a high proportion of general waste (7 bins), contained more than $50 \%$ loose tablets ( 5 bins) or contained unsafe waste, such as liquids, sharps or biological waste (9 bins).

\section{What is being returned?}

In total, 30422 different medicine items were counted. This included prescription medicines, dose administration aids (which may include multiple medicines), over-the-counter medicines and complementary medicines (see Box). These were in the form of unopened or opened packs, including loose countable forms of medicines e.g. a blister strip of tablets, but not loose tablets and capsules. For each item, the number of individual tablets and capsules or nebules was counted. For dose administration aids, creams, liquids and aerosols, the proportion returned was estimated.

\section{Box Types of medicines returned in a 2016 Return Unwanted Medicines Project audit}

$60 \%$ of the returned items were PBS medicines:

- $55 \%$ were prescription only (Schedule 4)

- $1 \%$ were controlled drugs (Schedule 8)

- $4 \%$ were pharmacist-only medicines

(Schedule 3 - these were assumed to be PBS medicines)

$10 \%$ of items were over-the-counter medicines

(Schedule 2).

$14 \%$ were dose administration aids.

$11 \%$ were unscheduled medicines.

$4 \%$ were complementary medicines.

$1 \%$ were international, and unknown schedule medicines.

PBS Pharmaceutical Benefits Scheme

The Table lists the 20 most commonly returned Pharmaceutical Benefits Scheme (PBS)-listed medicines identified in the 2016 audit and compares these to the most commonly dispensed PBS medicines in 2015-16 and to the results of a 2013 RUM Project audit. ${ }^{9-12}$

Not surprisingly, 10 of the most commonly prescribed PBS medicines in 2015-16 were included in the list of the 20 most commonly returned PBSlisted medicines in the 2016 audit. Six of the most commonly returned PBS medicines in 2016 are used for chronic conditions, and three - atorvastatin, simvastatin and metformin - were in the top 20 most prescribed PBS medicines (Table)
In comparing the 2016 and the 2013 RUM Project audit results, 11 PBS-listed medicines appear on both lists (Table). Salbutamol and glyceryl trinitrate appear in the top five of both audits. In 2013, 13 of the most commonly returned PBS medicines were 'if required' medicines. These were defined as items used for acute conditions such as nausea, acute infections, asthma or angina attacks, medicines that required regular dose adjustments (e.g. prednisolone, warfarin), and analgesics. Analgesics were included because, although pain can be acute or chronic, there are often dose adjustments and medicine changes for people with chronic pain conditions. The results revealed that in 2016 the top six were 'if required', as well as 14 of the 20 most commonly returned PBS-listed medicines. Just over a third (36\%) of all medicines returned in 2016 were expired, compared with 51\% in the 2013 audit. Approximately $10 \%$ of the PBS-listed medicines were expired and approximately $10 \%$ were unopened.

The 2016 audit attempted to calculate a cost to the PBS of wasted medicines. PBS waste was assumed to consist of all dispensed (i.e. had a dispensing label) and unopened PBS-listed medicines, irrespective of expiry. If a medicine had been opened and at least one dose taken, it was not considered as waste as it could have been discarded for valid reasons, including adverse events or poor efficacy. Using this definition, and assuming that the sample was representative of the total number of bins collected annually, the estimated cost of wasted medicines discarded via the RUM Project is approximately $\$ 11.6$ million a year.

\section{Is the system working?}

Yes, the RUM Project is working. It collected potentially dangerous medicines from consumers and prevented over 704 tonnes of expired or unwanted medicines ending up in landfill and the waterways in 2016. ${ }^{7}$ However, awareness of the RUM Project within the general population is low. As part of the 2016 audit, we conducted a survey of 4302 people and found that less than $18 \%$ had heard of it and most people dispose of unwanted medicines in the household rubbish or into the sewerage.

It appears that the RUM Project is being used appropriately by community pharmacy staff. Liquid cytotoxic agents, Schedule 8 items (without evidence of destruction in some states and without exception in other states) and sharps should not be disposed of in RUM bins. ${ }^{7}$ No liquid cytotoxic agents were found in the bins and only a small number of Schedule 8 items (1.6\%) were found.

Although 29 bins were excluded from the audit, only seven of 452 bins (1.5\%) were excluded because they 


\section{Table The most commonly dispensed and returned PBS-listed medicines in Australia}

\begin{tabular}{|c|c|c|c|}
\hline Rank & 2015-16 PBS prescription counts ${ }^{10}$ & 2016 audit of returned medicines ${ }^{9}$ & 2013 audit of returned medicines $* 11,12$ \\
\hline 1 & Atorvastatin & Paracetamol $^{\dagger}$ & Salbutamol ${ }^{\dagger}$ \\
\hline 2 & Rosuvastatin & Salbutamol $^{\dagger}$ & Insulin ${ }^{\ddagger}$ \\
\hline 3 & Esomeprazole & Glyceryl trinitrate ${ }^{\dagger}$ & Furosemide (frusemide) \\
\hline 4 & Paracetamol ${ }^{\dagger}$ & Cefalexin $^{\dagger}$ & Prednisolone/prednisone ${ }^{\dagger}$ \\
\hline 5 & Pantoprazole & Metoclopramide $^{\dagger}$ & Glyceryl trinitrate $^{\dagger}$ \\
\hline 6 & Perindopril & Doxycycline $^{\dagger}$ & Telmisartan/amlodipine \\
\hline 7 & Metformin & Furosemide (frusemide) & Fluticasone/salmeterol \\
\hline 8 & Pregabalin & Simvastatin & Paracetamol $^{\dagger}$ \\
\hline 9 & Fluticasone/salmeterol & Atorvastatin & Metoclopramide $^{\dagger}$ \\
\hline 10 & Salbutamol ${ }^{\dagger}$ & Aspirin & Warfarin $^{\dagger}$ \\
\hline 11 & Irbesartan & Warfarin $^{\dagger}$ & Influenza vaccine \\
\hline 12 & Cefalexin $^{\dagger}$ & Tramadol $^{\dagger}$ & Perindopril \\
\hline 13 & Atenolol & Oxycodone $^{\dagger}$ & Metoprolol \\
\hline 14 & Simvastatin & Pregabalin $^{\dagger}$ & Paracetamol/codeine ${ }^{\dagger}$ \\
\hline 15 & Oxycodone $^{\dagger}$ & Pantoprazole ${ }^{\dagger}$ & Atorvastatin \\
\hline 16 & Amoxicillin ${ }^{\dagger}$ & Amoxicillin $^{\dagger}$ & Amoxicillin ${ }^{\dagger}$ \\
\hline 17 & Amlodipine & Metformin & Betamethasone $^{\dagger}$ \\
\hline 18 & Paracetamol/codeine ${ }^{\dagger}$ & Prednisolone $^{\dagger}$ & Oxycodone ${ }^{\dagger}$ \\
\hline 19 & Amoxicillin/clavulanic acid ${ }^{\dagger}$ & Valproate & Cefalexin $^{\dagger}$ \\
\hline 20 & Ramipril & Amoxicillin/clavulanic acid ${ }^{\dagger}$ & Ipratropium ${ }^{+}$ \\
\hline
\end{tabular}

PBS Pharmaceutical Benefits Scheme RUM Return of Unwanted Medicines

* The 2013 audit was of 377 RUM bins. Although the processes were similar in the 2016 audit, the 2013 audit considered any quantity of a returned medicine as a full pack (i.e. the full dispensed amount). In the 2016 audit, the exact quantity of each medicine returned was counted.

+ Items that could be considered 'if required' (i.e. medicines for acute or short-term conditions, chronic conditions with unpredictable flare-ups, or medicines that require regular dose adjustments).

$\ddagger$ 'Insulin' in the 2013 audit included all types of insulins. In the 2016 audit, each type of insulin was counted separately. If all insulins were grouped together in the 2016 audit, 'insulin' would have been the third most commonly returned PBS-listed item.

contained inappropriate waste (over $50 \%$ of genera waste). Approximately $11 \%$ of bins contained sharps which included unused needles, syringes, lancets and blades.

\section{What could be improved?}

There is never going to be a situation when there are no wasted medicines, and, in fact, the return of medicines via the Project should be considered positive. For example, the return of any unused oxycodone and tramadol removes these potentially dangerous medicines from households. ${ }^{13}$

Based on the proportions of medicines returned, it could be argued that some 'if required' medicines for example, analgesics for acute pain - are being prescribed in excessive quantities. A recent study found that $42-71 \%$ of opioid tablets prescribed after surgery were unused..$^{13}$ While prescribing smaller quantities is often proposed as a way to reduce wastage, this may have negative impacts on consumer access and adherence to medicines, and may increase costs because of the need for more frequent prescribing and dispensing. Although it was beyond the scope of the 2016 audit, this could be an area of future research and economic analysis.

Awareness of the RUM Project could be improved. When provided with information about the Project, over $90 \%$ of survey respondents who were previously unaware of the Project stated that they would now use it. 
Although the proportion of general waste, liquid cytotoxics and Schedule 8 medicines was low, sharps were found in approximately $11 \%$ of RUM bins. This suggests that education of pharmacists and pharmacy staff about the correct disposal of sharps could be improved.

\section{Conclusion}

It is everyone's responsibility to reduce medicine waste and to be aware of which regular and 'if required' medicines are needed at the time of prescribing and dispensing. Education is critical to ensure that practices to minimise wastage are implemented. Prescription quantities need to be balanced with access, adherence and overall cost. However, despite our best efforts to minimise medicine waste, it will occur. The RUM Project is therefore a vital public service that provides a safe, easy and free way for consumers to dispose of unwanted medicines and it should be promoted by all health professionals. $<$

This project was funded by The National Return and

Disposal of Unwanted Medicines Limited and the

Australian Government Department of Health. The

researchers were independent from the funder. The

financial assistance provided must not be taken as

endorsement of the contents of this report.

Acknowledgement: The authors would like to thank

Alejandra Gallardo-Godoy and Joye Kerr for their

assistance with the RUM Project audit, the data

collection assistants from Brisbane, Perth and

Melbourne, and Nathan Zipf for developing the database

used in the Project.

\section{REFERENCES}

1. Bettington E, Spinks J, Kelly F, Gallardo-Godoy A, Nghiem S, Wheeler AJ. When is a medicine unwanted, how is it disposed, and how might safe disposal be promoted? Insights from the Australian population. Aust Health Rev 2017 Dec 19 [Epub ahead of print]. https://doi.org/10.1071/ AH16296

2. Bound JP, Voulvoulis N. Household disposal of pharmaceuticals as a pathway for aquatic contamination in the United Kingdom. Environ Health Perspect 2005;113:1705-11. https://doi.org/10.1289/ehp.8315

3. Bound JP, Kitsou K, Voulvoulis N. Household disposal of pharmaceuticals and perception of risk to the environment. Environ Toxicol Pharmacol 2006;21:301-7. https://doi.org/ 10.1016/j.etap.2005.09.006

4. Kotchen M, Kallaos J, Wheeler K, Wong C, Zahller M. Pharmaceuticals in wastewater: behavior, preferences, and willingness to pay for a disposal program. J Environ Manage 2009;90:1476-82. https://doi.org/10.1016/ j.jenvman.2008.10.002

5. Glassmeyer ST, Hinchey EK, Boehme SE, Daughton CG, Ruhoy IS, Conerly O, et al. Disposal practices for unwanted residential medications in the United States. Environ Int 2009;35:566-72. https://doi.org/10.1016/j.envint.2008.10.007

6. Department of Health. National Medicines Policy. Canberra: Commonwealth of Australia; 2011. http://www.health.gov.au/internet/main/publishing.nsf/ Content/National+Medicines+Policy-1 [cited 2018 May 1]

7. Medicines RU. The National Return \& Disposal of Unwanted Medicines Limited; 2018. www.returnmed.com.au [cited 2018 May 1]
8. Australian Government Department of Health. Quality use of medicines (QUM). Canberra: Commonwealth of Australia; 2011. www.health.gov.au/internet/main/publishing.nsf/ content/nmp-quality.htm [cited 2018 May 1]

9. Wheeler AJ, Kelly F, Spinks J, Bettington E. National Return and Disposal of Unwanted Medicines Project audit 2016. Final Report. Brisbane: Griffith University; 2016. http://www.returnmed.com.au/wp-content/ uploads/2017/08/NatRUM-Project-Final-Report-GriffithUniversity.pdf [cited 2018 May 1]

10. Department of Health. The Pharmaceutical Benefits Scheme. Expenditure and prescriptions twelve months to 30 June 2016. Canberra: Commonwealth of Australia; 2016. http://www.pbs.gov.au/info/statistics/pbs-expenditureprescriptions-30-june-2016 [cited 2018 May 1]

11. Bergen P, Kong D, George J, Hussainy S, Kirkpatrick C, Dooley M, et al. The National Return and Disposal of Unwanted Medicines (NatRUM) Project audit. Final Report. Melbourne: Monash University; 2013. http://auspharmacist.net.au/images/rumrep.pdf [cited 2018 May 1]

12. Bergen PJ, Hussainy SY, George J, Kong DC, Kirkpatrick CM. Safe disposal of prescribed medicines. Aust Prescr 2015;38:90-2. https://doi.org/10.18773/austprescr.2015.031

13. Bicket MC, Long JJ, Pronovost PJ, Alexander GC, Wu CL. Prescription opioid analgesics commonly unused after surgery: a systematic review. JAMA Surg 2017;152:1066-71. https://doi.org/10.1001/jamasurg.2017.0831 